\title{
Ferulic acid improves motor function induced by spinal cord injury in rats via inhibiting neuroinflammation and apoptosis
}

\author{
Xi Jiang ${ }^{1} \mathbb{D}$, Xuefeng $Y^{2 *} \mathbb{D}$, Jin Chen $^{3} \mathbb{D}$, Changfeng Jing ${ }^{4} \mathbb{D}$, Lexing $\mathrm{Xu}^{5} \mathbb{D}$, Ziwei Chen ${ }^{2} \mathbb{D}$, \\ Fuhe Liu $^{2}$ (D), Lei Chen² (D)
}

1. MM. Department of Pharmacy - Zhejiang University Mingzhou Hospital and Zhejiang Pharmaceutical College - Ningbo, China.

2. MM. Department of Pharmacy - Zhejiang Pharmaceutical College - Ningbo, China.

3. BM. Department of Pharmacy - Zhejiang University Mingzhou Hospital - Ningbo, China.

4. MM. Department of Pharmacy - Zhejiang University Mingzhou Hospital - Ningbo, China.

5. PhD. Department of Pharmacy - Zhejiang Pharmaceutical College - Ningbo, China.

\begin{abstract}
Purpose: To investigate the effect of ferulic acid (FA) on spinal cord injury (SCI)-induced motor dysfunction and to explore the possible pharmacological mechanisms. Methods: Adult male Wistar rats were used in our study. $\mathrm{SCl}$ was achieved by clipping the spinal cord T9 of the rat by a vascular clip for 2 minutes. The motor function of the rat was evaluated by Basso, Beattie, and Bresnahan scoring method (BBB) and inclined plane test. Hematoxylin and eosin (HE) staining, NISSL staining, and transmission electron microscopic examination were used to evaluate alterations at the histological level. Polymerase chain reaction (PCR), Western blots, and enzyme-linked immunosorbent assays (ELISA) were employed in biochemical analysis. Results: The BBB score and inclined plane test score significantly decreased after $\mathrm{SCl}$ surgery, whereas chronic FA treatment (dose of $90 \mathrm{mg} / \mathrm{kg}$, i.g.) for 28 days improved $\mathrm{SCl}$-induced motor dysfunction. $\mathrm{HE}$ staining showed that $\mathrm{SCl}$ surgery induced internal spinal cord edema, but the structural changes of the spinal cord could be reversed by FA treatment. NISSL staining and transmission electron microscopic examination confirmed the improvement of the effect of FA on the injury site. In the biochemical analysis, it could be found that FA inhibited $\mathrm{SCl}$-induced mRNA and protein overexpression of pro-inflammatory cytokines (IL-1 $\beta$, IL-6, TNF- $\alpha$ ), as well as iNOS and COX-2 via the modulation of NF- $\mathrm{KB}$ level in the spinal cord of SCl rat. Moreover, the $\mathrm{SCl}$-induced decrease of $\mathrm{Bcl}-2 / \mathrm{Bax}$ ratio was also reversed by FA treatment. However, the effect of FA on the expression of Beclin-1 was not statistically significant. Conclusion: FA showed a therapeutic effect on $\mathrm{SCl}$, which may be associated with the regulation of neuroinflammation and apoptosis.
\end{abstract}

Key words: Central Cord Syndrome. Apoptosis. Rats.

*Corresponding author: yuxf_2016@163.com | (55 86) 574-88223556

Received: Mar 15, 2021 | Review: May 17, 2021 | Accepted: Jun 12, 2021

Conflict of interest: Nothing to declare

Research performed at Department of Pharmacy, Zhejiang University Mingzhou Hospital, Ningbo, China. 


\section{Introduction}

Spinal cord injury ( $\mathrm{SCl}$ ) is a devastating trauma of the central nervous system (CNS) that seriously affects the quality of one's life ${ }^{1}$. The development of $\mathrm{SCl}$ includes primary injury and secondary injury. The primary injury usually refers to the physical injury caused by mechanical compression to the spinal cord at initial impact. Secondary injury is a series of complex pathological changes following the primary injury ${ }^{2}$. Since primary injury is irreversible, avoiding secondary injury becomes the key to the clinical treatments for $\mathrm{SCl}$.

As it is known, trauma to the spinal cord causes immediate nervous tissue injury, which leads to acute inflammatory and destroys blood vessels in the injury epicenter, and the vascular damage exacerbates inflammation of the damaged nerve tissue. In the process of immune response after $\mathrm{SCl}$, inflammatory cells, including $T$ cells, macrophages, as well as neutrophils, rapidly migrate and infiltrate the injury site $^{3}$. Subsequently, inflammatory cytokines such as IL-1 $\beta$, IL-6, and TNF- $\alpha$ were overexpressed in the injury epicenter ${ }^{4,5}$. As tissue-resident macrophages of CNS, microglial cells are activated after pathologic stimuli and produce large amounts of prostaglandin and nitric oxide, which are largely regulated by two inducible rate-limiting enzymes, COX-2 and iNOS ${ }^{6}$.

Apart from inflammatory response, apoptosis and autophagy, two different programmed cell death forms, were also demonstrated to play important roles in the secondary injury stage of $\mathrm{SCl}^{7}$. For example, Beclin-1, which is a well-established regulator of the autophagic pathway, has been implicated to be involved in the pathology of $\mathrm{SCl}^{8}$. Besides, Bax and $\mathrm{BCl}-2$ are two important factors associated with neural cell apoptosis ${ }^{9,10}$. Therapeutic interventions modulating the aforementioned cytokines relating to inflammatory response, cell apoptosis, and cell autophagy, three major pathogeneses of neuron loss, may be beneficial to diminish the secondary injury of $\mathrm{SCl}$.

Ferulic acid (FA), the main active ingredient of herbal medicine Angelica sinensis, possesses various pharmacological functions. For example, a previous study showed FA presented neuroprotective function against ischemia/reperfusion (I/R)-induced brain injury via suppressing oxidative stress and apoptosis ${ }^{11}$. Another basic research found FA protects hyperglycemia-induced kidney damage by regulating oxidative insult, inflammation, and autophagy ${ }^{12}$. Though the protective effect of FA on $\mathrm{SCl}$ has been reported in a few studies ${ }^{13,14}$, the underlying mechanism is largely unexplored.

The present study was designed to investigate FA's effect on $\mathrm{SCl}$ by evaluating the motor function of rats before and after $\mathrm{SCl}$ surgery. The expressions of inflammatory-related mediators (NF-KB, IL-1 $\beta$, IL-6 TNF- $\alpha$, iNOS, and COX-2), apoptosis-related proteins (i.e. Bcl-2, Bax), and autophagy-related factor Beclin-1 were tested to disclose the mechanisms associating with $\mathrm{FA}^{\prime}$ s possible positive function on $\mathrm{SCl}$.

\section{Methods}

All the experimental procedures were approved by Zhejiang Pharmaceutical College Animal Care and Use Committee (approval number: wydw2017-0051) and conducted according to the guidelines set forth by Chinese National Institutes of Health. In the experiment, five animals were lost due to $\mathrm{SCl}$, and another five were used as substitutes. Thus, a total of 55 rats was used in this study.

Adult male Wistar rats (220-240 g) were purchased from Shanghai Animal Center of Chinese Academy of Science. The rats were housed five per cage under controlled environmental conditions. Once arrived, the rats adapted to the environment for one week and later were used in the experiment. Fifty rats were evenly allocated into five groups: sham (animal received surgical operation without $\mathrm{SCl}$ ), $\mathrm{SCl}$, and $\mathrm{SCl}+\mathrm{FA}$ groups, the latter divided into doses of $10,30,90 \mathrm{mg} / \mathrm{kg}$, i.g.

\section{Treatment schedule}

The rats received $\mathrm{SCl}$ surgery except the sham group. After the surgery, rats received FA (doses of $10,30,90 \mathrm{mg} / \mathrm{kg}$, i.g.), which was dissolved by carboxymethyl cellulose sodium for 28 consecutive days (each day at 8 a.m.). The dose of FA was selected based on a previous study ${ }^{15}$. Each animal received a behavioral test on days $0,7,14,21$, and 28 post-surgery. On day 28 , rats were anesthetized by pentobarbital (4 mg per $100 \mathrm{~g}$ body weight, i.p.). For histological experiments, rats ( $n=5$ in each group) were perfused with saline, followed by formaldehyde phosphate buffered saline (PBS) solution. For biochemical experiments, the clean spinal cord tissues (from T8 to T10) of the rats ( $n=5$ in each group) were retrieved after perfusion with saline. The experimental design is summarized in Fig. 1 a. 


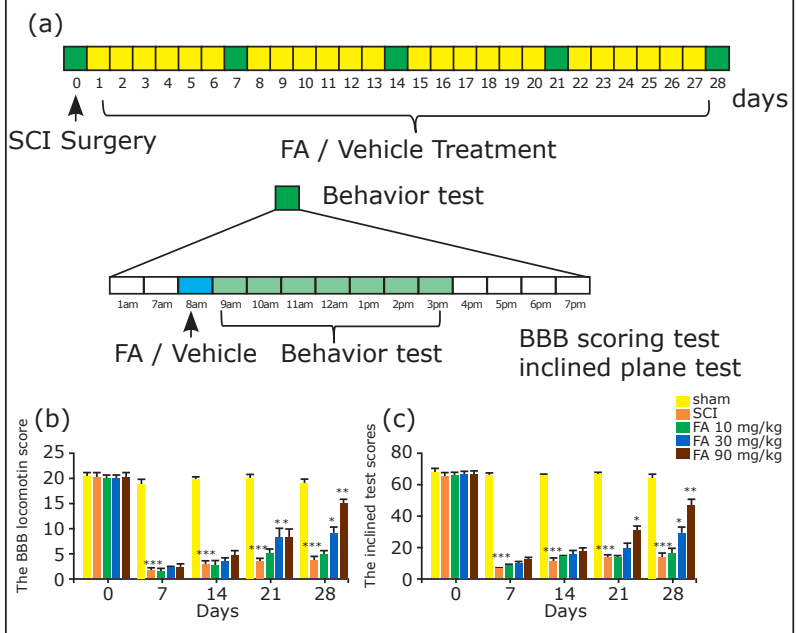

SCI: spinal cord injury; FA: ferulic acid; BBB: Basso, Beattie, and Bresnahan scoring method; SEM: standard error of mean.

Figure 1 - (a) Experimental design. $\mathrm{SCl}$ model was established by creating a moderate spinal cord compression using a vascular clip. The sham group received the same surgical procedures without compression generated by vascular clip. After $\mathrm{SCl}$ surgery, rats received FA $(10,30,90 \mathrm{mg} / \mathrm{kg}$, i.g.) or vehicle (CMC-Na) for 28 days. BBB scoring method and inclined plane test were performed to assess the motor function of rats on days $0,7,14,21$, and 28 post-surgery. Animals were sacrificed on the 28th day after behavior tests for neurochemical analysis. Effects of $\mathrm{FA}(10,30,90 \mathrm{mg} / \mathrm{kg}$, i.g.) on $\mathrm{SCl}$ rats in (a) the BBB locomotion test and (b) inclined plane test. Data are presented as mean \pm SEM, $n=10$ in each group. $* * * p<0.001$ when compared with the sham group; $\# p<0.05$ and \#\#p<0.01 when compared with SCl group.

\section{Spinal cord injury surgery}

$\mathrm{SCl}$ surgery was performed as previously described ${ }^{16}$. Firstly, the rat was anesthetized by pentobarbital $(4 \mathrm{mg}$ per $100 \mathrm{~g}$ body weight, i.p.) and, then, placed in a prone position on a platform, and all four feet were fixed. Afterward, the spinal cord T9 was exposed and clipped by a vascular clip for 2 minutes (30 g forces, Oscar, China) to induce SCl. Postoperative care included bladder massage twice a day for three days and passive mobilization of hind legs three times a day.

\section{Motor function test}

The locomotor function of rats was evaluated by BBB scoring test ${ }^{16}$ and inclined plane test ${ }^{17}$ on days $0,7,14,21$, and 28 after $\mathrm{SCl}$. In the BBB scoring test, the activity of the hind limb of each animal was videotaped and recorded by three blinded observers. $\mathrm{BBB}$ scores ranging from 0 to 21 represent the state from no hind limb movement to normal gait. In the inclined plane test, the maximum angle at which the animal could maintain for 5 seconds without falling was the data of this test.

\section{Hematoxylin and eosin staining and NISSL staining}

The retrieved spinal cord tissue was embedded in paraffin. The lesion epicenter was stained with hematoxylin and eosin (HE staining) or cresyl violet (NISSL staining), according to the standard protocols (HE Staining Kit and NISSL Staining Kit, purchased from Beijing Solarbio Science \& Technology, Beijing, China). All stained sections were further observed under a light microscope (Nikon, Minato, Tokyo, Japan).

\section{Transmission electron microscopic examination}

The retrieved spinal cord tissue was bathed in 2.5\% glutaraldehyde for 2 hours. The samples were dehydrated and washed, and then post-fixed in $1 \%$ osmium tetroxide including $0.8 \%$ potassium ferrocyanide and $0.1 \mathrm{M}$ cacodylate buffer containing $5 \mathrm{nM}$ calcium chloride for 90 minutes. After that, the samples were dehydrated in graded acetone, infiltrated with Poly/Bed 812 resin (Polysciences, Washington, PA, United States) and polymerized for 60 hours. Five hundred-nanometer-thick sections were cut on an ultramicrotome (Leica Ultracut UCT) and stained with toluidine blue. Images were obtained using a digital camera (DP 11, Japan) attached to a microscope (Olympus Ax70).

\section{Quantitative real-time polymerase chain reaction}

The mRNA levels of L- $1 \beta$, IL- 6 , TNF- $\alpha$, iNOS, and COX- 2 in the spinal cord were measured by quantitative realtime polymerase chain reaction (qRT-PCR). Total RNA was isolated using Trizol reagent (Trizol Invitrogen) according to the manufacturer's protocol, and RNA (1 mg) was reversely transcribed using MJ Mini Gradient Thermal Cycler (Bio-Rad Laboratories, Hercules, CA, United States). RNA concentration was determined using a spectrophotometer (Bio-Rad Laboratories) at $260 \mathrm{~nm}$. Subsequently, extracted RNA was reversely transcribed into complementary deoxyribonucleic acid (cDNA) following PrimeScript RT reagent Kit (Otsu, Shiga, Japan). SYBR Green (iQ SYBR Green supermix reagent, Bio-Rad Laboratories) was added to each sample at a concentration of $50 \mathrm{nmol} / \mathrm{L}$.

The protocol of the real-time PCR was as follows: initial denaturation at $95^{\circ} \mathrm{C}$ for $10 \mathrm{~min}$, followed by 40 cycles at $95^{\circ} \mathrm{C}$ for $10 \mathrm{~s}$, and $58^{\circ} \mathrm{C}$ for $30 \mathrm{~s}$. At the end of the PCR reaction, a melting curve was obtained by holding at $95^{\circ} \mathrm{C}$ for $15 \mathrm{~s}$, cooling to $60^{\circ} \mathrm{C}$ for $1 \mathrm{~min}$, and then heating slowly at $0.5^{\circ} \mathrm{C} / \mathrm{s}$ until $95^{\circ} \mathrm{C}$. PCR products were amplified in the real-time PCR machine followed by melt curve analysis. All the data were normalized to the housekeeping gene $\beta$-actin. The primer sequences were listed in Table 1. 
Table 1 - The primer sequences of target mRNAs.

\begin{tabular}{ccc}
\hline Target & Forward $\left(\mathbf{5}^{\prime} \mathbf{-} \mathbf{3}^{\prime} \mathbf{)}\right.$ & Reverse $\left(\mathbf{5}^{\prime}-\mathbf{3}^{\prime}\right)$ \\
\hline IL-1 $\beta$ & TGGACTTCGCAGCACAAAATG & GTTCACTTCACGCTCTTGGAT \\
IL-6 & CCAGAAACCGCTATGAAGTTCCT & CACCAGCATCAGTCCCAAGA \\
TNF- $\alpha$ & GCTGGATCTTCAAAGTCGGGT GTA & TGTGAGTCTCAGCACACTTCCATC \\
iNOS & CCTCCTCCACCCTACCAAGT & CACCCAAAGTGCTTCAGTCA \\
COX-2 & TGGGTGTGAAAGGAAATAAGGA & GAAGTGCTGGGCAAAGAATG \\
$\beta$-actin & TGGAATCCTGTGGCATCCATGAAAC & AAAACGCAGCTCAGTAACAGTCCG \\
\hline
\end{tabular}

Western-blot analysis

The protein levels of Bcl-2, Bax, and Beclin-1 were detected by Western-blot assay. The spinal cord tissue was incubated with RIPA lysis buffer (Millipore Chemicon, Temecula, CA, United States), and then the supernatant was obtained by centrifugation. The protein concentration of each sample was determined by BCA assay kit (Thermo Fisher Scientific, Waltham, MA, United States), and $40 \mu \mathrm{g}$ protein was included in each band. After electrophoresis and membrane transfer, the blots were incubated with blocking buffer for $2 \mathrm{~h}$, washed by washing buffer, and incubated with primary antibodies-anti-Beclin-1 1:400, purchased from Santa Cruz Biotechnology (Dallas, TX, United States); anti-Bcl-2 1:2,000, anti-bax 1:1,000, and anti- $\beta$-actin 1:1,000, purchased from Abcam Plc (Cambridge, United Kingdom). Afterward, the blots were incubated with secondary antibodies (1:10,000) and finally imaged by fluorescence scanner (Odyssey Infrared Imaging System, South San Francisco, CA, United States).

\section{Enzyme-linked immunosorbent assay}

Expressions of NF- $\mathrm{KBp} 65$ and pro-inflammatory cytokines (IL-1 $\beta$, IL-6, and TNF- $\alpha$ ) in the spinal cord were tested by enzyme-linked immunosorbent assay (ELISA) kits purchased from R\&D System (Minneapolis, United States). The levels of iNOS and COX-2 in the spinal cord were detected by ELISA detection kits obtained from Abcam (Shanghai, China). In the experiment, the protein standard and sample solutions were firstly added into a 96-well plate respectively, followed by the addition of the anti-antibody. After washing, a mixture containing avidin and horseradish peroxidase was added to the plate. The reaction was stopped by the terminating solution, and the optical density (OD) values of IL-1 $\beta$, IL-6, TNF- $\alpha$, iNOS, and COX-2 were tested by spectrophotometer at $450 \mathrm{~nm}$ wavelength. Only the OD value of NF-KBp65 was measured at $405 \mathrm{~nm}$ wavelength. The concentration of each sample was obtained by using the standard curve provided by the manufacturer based on the OD value.

\section{Statistical analysis}

SPSS software (International Business Machines Corporation, Endicott, NY, United States) was used for data analysis. Multiple-group comparisons were analyzed by one-way analysis of variance (ANOVA). Two-group comparisons were analyzed by the Dunnett's test. The results were presented as mean \pm standard error mean (SEM), with $p<0.05$ being considered as a statistical difference.

\section{Results}

\section{Effects of ferulic acid on the locomotor function of rats}

As shown in Fig. 1b, $\mathrm{SCl}$ surgery led to a significant decrease of $\mathrm{BBB}$ score in the $\mathrm{SCI}$ group when compared with the sham group $(p<0.001)$. However, the BBB score gradually increased with the chronic treatment of FA, especially at $90 \mathrm{mg} / \mathrm{kg}$, and the maximal effect of FA was observed on day 28 post-surgery at the concentration of $90 \mathrm{mg} / \mathrm{kg}(\mathrm{p}<0.01)$. Similarly, the angle of incline reduced markedly after SCI ( $<<0.001)$ (Fig. 1C), whereas FA $(90 \mathrm{mg} / \mathrm{kg}$, i.g.) relieved this adverse effect, particularly on day 28 post-surgery ( $p<0.01$ ). Based on these behavioral results, FA was shown to protect the rats from motor dysfunction induced by $\mathrm{SCl}$.

\section{Spinal cord histology of rats}

As seen in Fig. 2a, normal spinal cord neurons had clear cell outlines and cytoplasm with uniform nuclei, while in $\mathrm{SCl}$ rats the lesion center was characterized by the destruction of gray and white matter. The neurons in the anterior horn shrunk or had pale homogenous cytoplasm. The injured tissue was prominently repaired after 28 days of FA treatment. The repairment was manifested by the recovery of nuclei and morphology and reduction of organization air conditioning in spinal gray matter. 


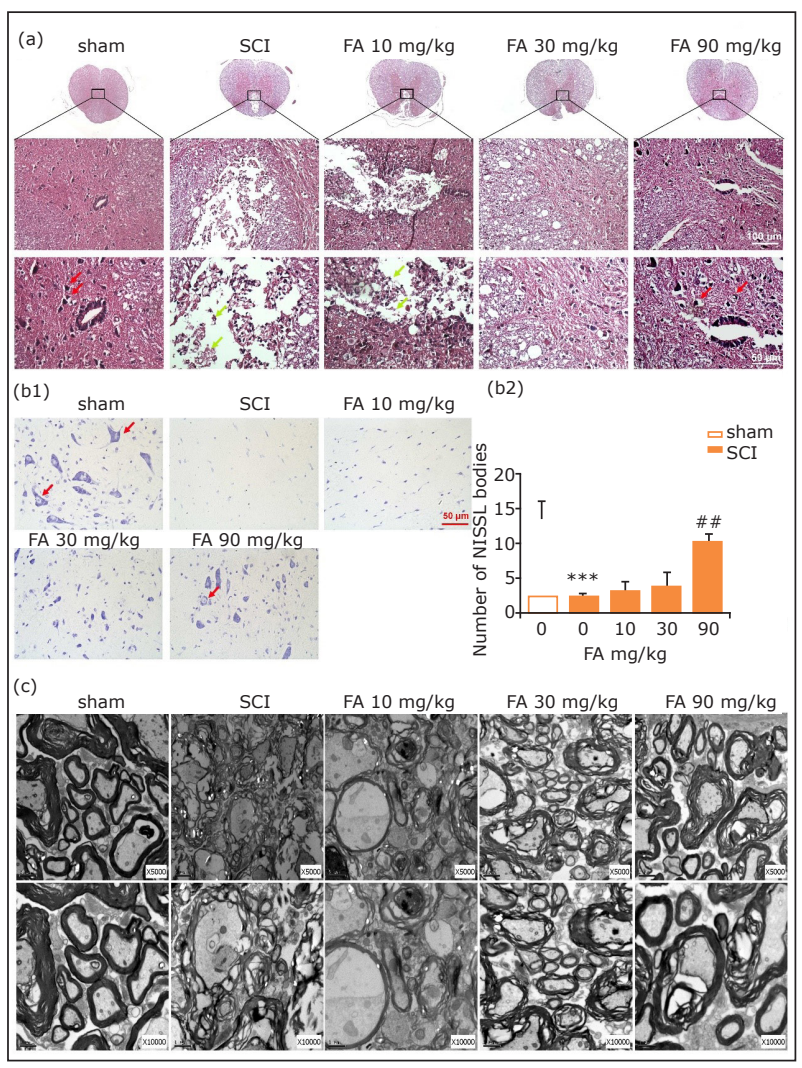

$\mathrm{SCl}$ : spinal cord injury; FA: ferulic acid; HE: hematoxylin \& eosin; SEM: standard error of mean.

Figure 2 - (a) HE staining on transverse section of the spinal cord of $\mathrm{T9}$ in rats at the 28th day after spinal cord injury (the first row is $\times 50$, the second is $\times 200$ and the third is $\times 400)$. Red arrow: normal nerve cells, green arrow: lesion site after spinal cord injury. (b) NISSL staining $(\times 40)$ on transverse section of spinal cord T9 in rats and quantitative analysis of NISSL bodies in staining images ( $n=4$ in each group), scale bar $=50 \mu \mathrm{m}$. Red arrow: NISSL bodies. (c) Ultrastructural morphology of myelin sheath and neuronal cells in the dorsal column and epicenter surrounding the gray matter of different groups. Data are presented as mean \pm SEM. $* * * p<0.001$ when compared with sham group; \#\#p $<0.01$ when compared with $\mathrm{SCl}$ group.

Similarly, in rats undergoing SCI surgery, NISSL bodies in the anterior horns were significantly decreased when compared with the sham group at the 28th day $(p<0.001$, Fig. 2b). However, FA treatment reversed $\mathrm{SCl}$-induced decreasing of NISSL bodies ( $p<0.01)$. These results confirmed the neuroprotective effect of FA on $\mathrm{SCl}$ rats.

\section{Spinal cord neurons morphology of rats}

To further confirm the beneficial effect of $\mathrm{FA}$ on $\mathrm{SCl}$ rats, ultrastructural analysis of the epicenter and its surrounding area was performed on day 28 post-surgery (Fig. 2c). In the sham group, nerve cells showed normal morphology, and the axons were myelinated with a compact multilayered sheath. SCI surgery-induced obvious cellular damage, including dissolved cavitation, karyopyknosis and degenerated myelin sheath with a loose state. However, FA treatment revised these phenomena, especially at the concentration of $90 \mathrm{mg} / \mathrm{kg}$.

\section{Effect of ferulic acid on NF- $\kappa B$ expression in rats}

As shown in Fig. 3a, the expression level of pNF-KB p65 in the spinal cord was notably enhanced after $\mathrm{SCl}(\mathrm{p}<0.001)$. Treatment with FA $(90 \mathrm{mg} / \mathrm{kg}, \mathrm{i} . \mathrm{g}$. suppressed $\mathrm{SCl}$-increased NF- $\mathrm{KB}$ p 65 phosphorylation level $(p<0.01)$.

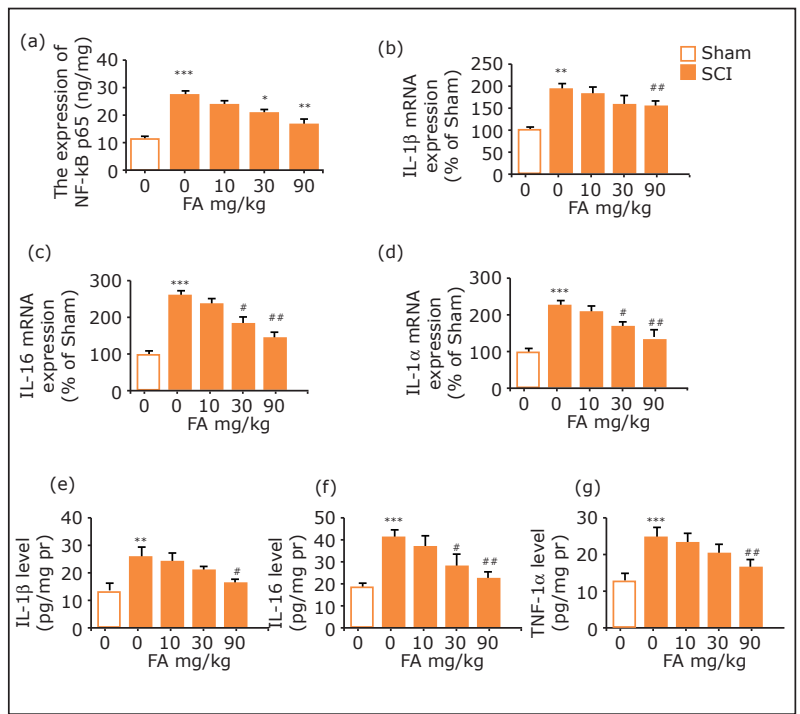

SCI: spinal cord injury; FA: ferulic acid; SEM: standard error of mean.

Figure 3 - (a) Effects of FA on NF-KBp65 expression in the spinal cord. (b-d) Effects of FA on mRNA expressions of IL-1 $1 \beta$, IL-6, and TNF- $\alpha$ in the spinal cord. (e-g) Effects of FA on expressions of IL-1 $\beta, \mathrm{IL}-6$, and TNF- $\alpha$ in spinal cord. Data are presented as mean \pm SEM, $n=5$ in each group; $* * p<0.01$ and $* * * p<0.001$ when compared with the sham group; $\# p<0.05$ and $\# \# p<0.01$ when compared with $\mathrm{SCl}$ group.

\section{Effects of ferulic acid on inflammatory factors} IL-1 $\beta, I L-6$, TNF- $\alpha$, COX-2, and iNOS expressions in rats

$\mathrm{SCl}$ surgery led to significant increases in the mRNA levels of IL-1 $\beta$, IL-6, and TNF- $\alpha$ in the spinal cord $(p<0.01$ 
for IL-1 $\beta$, and $p<0.001$ for IL- 6 and TNF- $\alpha$ ). Nevertheless, these increases were reversed by chronic treatment with FA ( $p<0.01$ for IL-1 $\beta$, IL-6, and TNF- $\alpha$, Fig. 3b-d). Results of the ELISA assay showed significant increases of IL-1 $\beta$, IL- 6 and TNF- $\alpha$ expressions in the spinal cord after SCI $(p<0.01$ for IL- $1 \beta$ and TNF- $\alpha$, and $p<0.001$ for IL-6, Fig. 3e-g), whereas FA treatment reversed the increases of IL-1 $\beta$, IL- 6 and TNF- $\alpha$ ( $p<0.05$ for IL-1 $\beta$, and $p<0.01$ for IL- 6 and TNF- $\alpha$ ).

As shown in Fig. 4a-b, $\mathrm{SCl}$ led to significant increases in mRNA levels of iNOS and COX-2 in the spinal cord when compared with the sham group $(p<0.001$ for iNOS and COX-2). Treatment with FA at $90 \mathrm{mg} / \mathrm{kg}$ markedly reversed the increased iNOS and COX-2 levels ( $p<0.01$ for iNOS and (OX-2). A similar phenomenon could be found in the results on iNOS and COX-2 protein expressions, as illustrated in Fig. 4c-d.

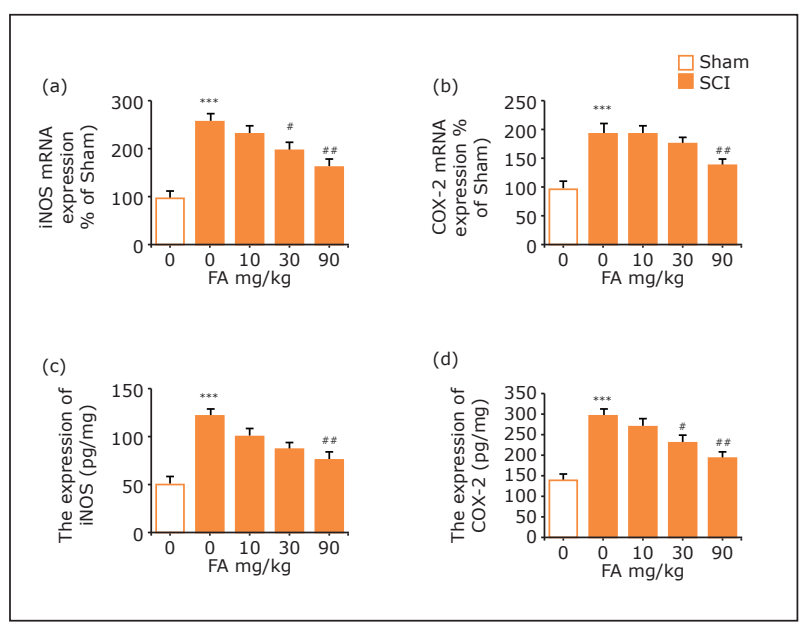

SCl: spinal cord injury; FA: ferulic acid; SEM: standard error of mean.

Figure 4 - Effects of FA on mRNA expressions of (a) iNOS and (b) COX-2 in the spinal cord. Effects of FA on protein expressions of (c) iNOS and (d) COX-2 in the spinal cord. Data are presented as mean \pm SEM, $\mathrm{n}=5$ in each group; ${ }^{* *} \mathrm{p}<0.01$ and $* * * p<0.001$ when compared with sham group; \#p<0.05 and \#\#p<0.01 when compared with $\mathrm{SCl}$ group.

\section{Effects of ferulic acid on Bcl-2, Bax, and Beclin-1 expressions in $\mathrm{SCl}$ rats}

$\mathrm{SCl}$ surgery led to a significant decrease in the ratio of Bcl-2/Bax ( $p<0.01$, Fig. 5 a1-a2). FA (90 mg/kg) treatment for 28 days improved this phenomenon $(p<0.05)$. For Beclin-1 expression, no significant difference could be observed between different groups (Fig. 5b1-b2).

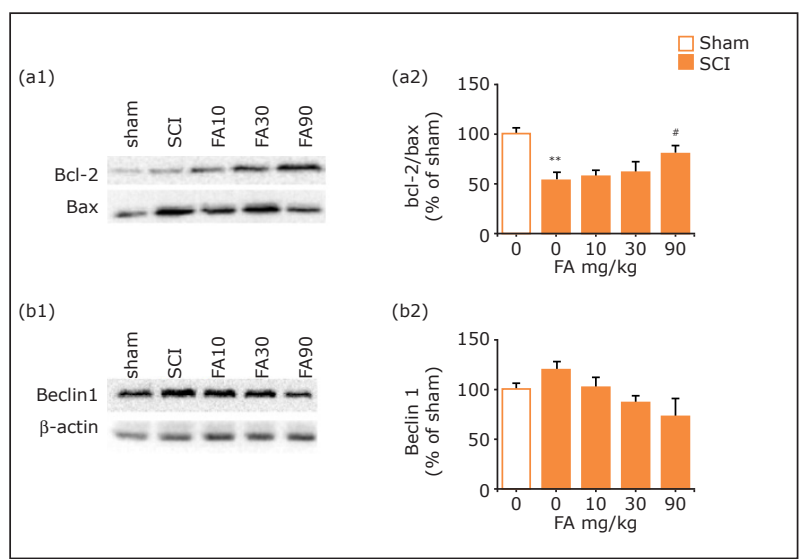

SCI: spinal cord injury; FA: ferulic acid; SEM: standard error of mean.

Figure5-Effects ofFAon (a1-a2) Bcl-2/Baxratioand (b1-b2) Beclin-1 in the spinal cord. (a1) Blots of Bcl-2 and Bax; (b1) Blots of Beclin-1 and $\beta$-actin; (a2-b2) Quantitative analysis of Bcl-2, Bax, and Beclin-1 expressions in Western-blot assay. Data are presented as mean \pm SEM, $\mathrm{n}=5$ in each group; ${ }^{* *} \mathrm{p}<0.01$ when compared with the sham group; $\# \mathrm{p}<0.05$ when compared with $\mathrm{SCl}$ group.

\section{Discussion}

In our study, FA was found to have protective efficacy against motor dysfunction in $\mathrm{SCl}$ rats. This beneficial effect was related to the modulation of inflammatory mediators (i.e., NF-KBp65, IL-1 $\beta$, IL-6, TNF- $\alpha$, COX-2, and iNOS) and apoptosis-related proteins (i.e. Bcl-2, Bax) in injured nervous tissue by FA.

$\mathrm{SCl}$ model is a well-established animal model leading to motor dysfunction and structural lesions of the spinal cord ${ }^{16,18}$. In our study, SCl surgery-induced motor dysfunction, which was evidenced by significant decreases of $\mathrm{BBB}$ score and angle of the incline in $\mathrm{SCl}$ rats. The further histological evaluation indicated $\mathrm{SCl}$ surgery-induced structural destruction of gray and white matter. Besides, a significant decrease of NISSL bodies in $\mathrm{SCl}$ rats also revealed the pathologic change in the spinal cord tissue. Moreover, the spinal cord neuron damage in $\mathrm{SCl}$ rats was observed by ultrastructural analysis. The aforementioned results indicated that the $\mathrm{SCl}$ rat model in our study was successfully established.

The neuroprotective function of FA had been discovered in several previous studies ${ }^{11,19-21}$, while studies concerning the protective function of FA on $\mathrm{SCl}$ were very limited. In the relevant study by Wei et al. ${ }^{14}$, it was proved that the systemic function of FA combined with glycol chitosan could improve functional recovery of rats after acute $\mathrm{SCl}$. In the present study, we evaluated the effect of FA on rats suffered 
from $\mathrm{SCl}$. Behavior tests showed significant recovery of motor function in $\mathrm{SCl}$ rats after FA treatment. Importantly, results of histopathological examinations confirmed the neuroprotective effect of chronic FA treatment on nerve trauma in $\mathrm{SCl}$ rats.

Neuroinflammation is thought to play a pivotal role in the secondary injury stage after $\mathrm{SCl}^{17,18}$. NF- $\mathrm{KB}$, the nuclear transcription factor, is a critical regulator of various proinflammatory cytokines ${ }^{22,23}$. Recently, evidence suggested that NF- $\mathrm{KB}$ signal pathway may be involved in the underlying neurobiological mechanism of $\mathrm{SCl}^{24}$. To know whether $\mathrm{NF}-\mathrm{KB}$ is involved in the improvement effect of $\mathrm{FA}$ on $\mathrm{SCl}$, we measured the expression level of NF- $\mathrm{KB} p 65$, which is a relevant protein involved in NF- $\mathrm{KB}$ heterodimer formation and nuclear translocation and activation ${ }^{25}$. Results indicated that NF-KB p65 was up-regulated in the spinal cord after $\mathrm{SCl}$, and it was down-regulated by FA treatment, suggesting that $\mathrm{FA}^{\prime}$ s positive function on $\mathrm{SCl}$ rats was achieved by inhibiting neuroinflammation through regulating NF-KB.

As downstream factors of NF- KB, IL- $1 \beta, I L-6$, and TNF- $\alpha$ have been reported to play important roles in the development of $\mathrm{SCl}^{26,27}$. For example, Habgood found TNF- $\alpha$ was highly expressed about 30-45 min after SCl, and expressions of IL- $1 \beta$ and IL- 6 were also significantly increased 3-24 $\mathrm{h}$ after SCl${ }^{4}$. Moreover, TNF- $\alpha$ activates resident Schwann cells and accelerates macrophage recruiting to the injury site, which induced a series of inflammatory reaction $\mathrm{s}^{28}$. In our study, IL-1 $\beta$, IL-6, and TNF- $\alpha$ levels were significantly increased after $\mathrm{SCl}$ surgery, and FA treatment reversed the $\mathrm{SCl}$-induced neuroinflammation.

Although FA's anti-inflammation function has been reported in the brain, there are very few studies focusing on its anti-inflammatory effect in the spinal cord. Our data indicated that the improvement effect of $\mathrm{FA}$ on $\mathrm{SCl}$ may be due to the regulation of IL-1 $\beta$, IL- 6 and TNF- $\alpha$ through regulating NF- $K B$. In addition to IL- $1 \beta$, IL-6, and TNF- $\alpha$, COX- 2 and iNOS are important roles in the pathogenesis of neurological diseases. They had been proved to remarkably increase under the regulation of NF-KB in stimulated microglial cells in rat's brain, which constitutes the inflammatory processes ${ }^{29,30}$. iNOS and COX-2 were also demonstrated to be involved in the pathophysiology of $\mathrm{SCl}^{31}$. Suppressing of COX-2 and iNOS after spinal cord trauma has been found to exert neuroprotective effects ${ }^{32,33}$. Our results indicated iNOS expression was increased after $\mathrm{SCl}$, and $\mathrm{FA}$ treatment inhibited the production of iNOS. Moreover, increased expression of COX-2 was also observed in our study, and FA reversed this phenomenon. Therefore, we hypothesize that the improvement effect of $\mathrm{FA}$ on $\mathrm{SCl}$ may also be associated with its inhibition of iNOS and COX-2 by regulating NF-KB.
In addition to the neuroinflammation mechanism, apoptosis also plays a critical role in the secondary damage of $\mathrm{SCl}^{34}$. Apoptosis refers to programmed cell death under precise regulation, which is executed by some evolutionarily conserved families, such as $\mathrm{Bcl}-2$ and caspase families ${ }^{35}$. As for the $\mathrm{Bcl}-2$ family, the degree of apoptosis is generally decided by the ratio of $\mathrm{Bcl}-2 / \mathrm{Bax} . \mathrm{Bcl}-2$ is an antiapoptotic member, and Bax is a pro-apoptotic protein in the $\mathrm{Bcl}-2$ family. Decreased expression of $\mathrm{BCl}-2$ could leave Bax unopposed and promote apoptosis ${ }^{36}$. Our results showed that $\mathrm{FA}$ revised $\mathrm{SCl}$-induced increased ratio of $\mathrm{Bcl}-2 / \mathrm{Bax}$, suggesting $F^{\prime}$ 's neuroprotective function may be related to its anti-apoptotic effect.

Autophagy is another mechanism involved in the development of $\mathrm{SCl}$. Via the autophagy pathway, certain toxins and pathogens are wrapped, degraded, and then eliminated ${ }^{37}$. Beclin-1 is an autophagy-related gene and a direct executor of autophagy ${ }^{38}$. In our data, Beclin-1 showed a trend of increase after $\mathrm{SCl}$ and decrease after FA treatment, but the result had no statistical difference. Autophagy and apoptosis are interrelated to a consistent degree. When anti-apoptotic proteins (i.e., $\mathrm{Bcl}-2$, caspase) are activated, autophagy marker proteins (i.e., Beclin-1) will decrease, leading to the inhibition of autophagy ${ }^{39}$. On the contrary, increased anti-apoptotic proteins (i.e., $\mathrm{Bcl}-2$, caspase) lead to autophagy activation ${ }^{7,40}$. Though a significant difference of Beclin-1 between distinct groups was not observed in our study, we speculate that the effect of $\mathrm{FA}$ on $\mathrm{SCl}$ was probably associated with inhibition of autophagy in consideration of the relationship between apoptosis and autophagy. However, more data need to be obtained in future studies to validate our speculation.

Our data revealed the beneficial effect of FA on $\mathrm{SCl}$ and the possible mechanisms. Despite these important findings, limitations should not be ignored. Firstly, the Beclin-1 expression only showed an increasing trend with no statistical significance, the anti-autophagy mechanism needs to be further confirmed. Second, as for the anti-inflammation and anti-apoptotic mechanisms, we only tested the expressions of several related cytokines, critical enzymes or factors involved in the pathways that had not yet been identified. Finally, the relationship between anti-inflammation, antiapoptotic, and anti-autophagy mechanisms involved in the beneficial function of FA was not investigated, which deserves further exploration.

\section{Conclusions}

The present study demonstrated that $\mathrm{FA}$, a naturally occurring molecule, can ameliorate the motor dysfunction induced by $\mathrm{SCl}$ surgery in rats, indicating FA is a potential 
candidate for clinical SCI therapy. This positive function of FA may be achieved by suppressing neuroinflammation and apoptosis, through regulating the levels of inflammatory cytokines IL-1 $\beta$, IL-6 TNF- $\alpha$, iNOS, and COX-2 and apoptosisrelated protein Blc-2/Bax. Further studies need to be done to investigate the specific signaling pathways involved in FA's function on $\mathrm{SCl}$.

\section{Author's contribution}

Conception the study: Chen J, Jing C, Chen L, Xu L, Liu $F$ and Chen Z; Design the study: $Y u X$ and Jiang $X$; Analysis of data: Chen J, Jing C, Chen L, Xu L, Liu F and Chen Z; Manuscript writing: Jiang $X$; Critical revision: $Y u$ $X$; Final approval: Jiang X, Yu X, Chen J, Jing C, Xu L, Chen $Z$, Liu F and Chen L.

\section{Data availability statement}

Data will be available upon request.

\section{Funding}

Zhejiang Province Public Welfare Technology Application Research Project

[https://doi.org/10.13039/501100010248]

Grant no LGF18H090014

Science and Technology Project of Zhejiang Medical and Health Department

Grant no 2020KY289

Ningbo Natural Science Foundation

[https://doi.org/10.13039/100007834]

Grant no 2019A610300 and 2019A610301

Science and Technology Project of Yinzhou, Ningbo Natural Science Foundation

Grant no 2019A610320

Natural Science Foundation of Zhejiang Province

[https://doi.org/10.13039/501100004731]

Grant no Q2OH010022

Zhejiang Province Public Welfare Technology Application Research Project

[https://doi.org/10.13039/501100010248]

Grant no LGF18H090029

\section{Acknowledgments}

Not applicable.

\section{References}

1. Singh A, Tetreault L, Kalsi-Ryan S, Nouri A, Fehlings MG. Global prevalence and incidence of traumatic spinal cord injury. Clin Epidemiol. 2014;6:309-31. https://doi. org/10.2147/CLEP.S68889.

2. Silva NA, Sousa N, Reis RL, Salgado AJ. From basics to clinical: a comprehensive review on spinal cord injury. Prog Neurobiol. 2014;114:25-57. https://doi. org/10.1016/j.pneurobio.2013.11.002

3. Haggerty $A E$, Maldonado-Lasuncion I, Oudega M. Biomaterials for revascularization and immunomodulation after spinal cord injury. Biomed Mater. 2018;13(4):044105. https://doi.org/10.1088/1748-605X/aaa9d8

4. Habgood MD, Bye N, Dziegielewska KM, Ek CJ, Lane MA, Potter A, Morganti-Kossmann C, Saunders NR. Changes in blood-brain barrier permeability to large and small molecules following traumatic brain injury in mice. Eur J Neurosci. 2007;25(1):231-8. https://doi.org/10.1111/ j.1460-9568.2006.05275.x

5. Pineau I, Lacroix S. Proinflammatory cytokine synthesis in the injured mouse spinal cord: multiphasic expression pattern and identification of the cell types involved. J Comp Neurol. 2007;500(2):267-85. https://doi.org/10.1002/ cne. 21149

6. Minghetti L, Levi G. Microglia as effector cells in brain damage and repair: focus on prostanoids and nitric oxide. Prog Neurobiol. 1998;54(1):99-125. https://doi. org/10.1016/s0301-0082(97)00052-x

7. Xia Y, Xia H, Chen D, Liao Z, Yan Y. Mechanisms of autophagy and apoptosis mediated by JAK2 signaling pathway after spinal cord injury of rats. Exp Ther Med. 2017;14(2):158993. https://doi.org/10.3892/etm.2017.4674

8. Abbaszadeh F, Fakhri S, Khan H. Targeting apoptosis and autophagy following spinal cord injury: Therapeutic approaches to polyphenols and candidate phytochemicals. Pharmacol Res. 2020;160:105069

9. Mao W, Yi X, Qin J, Tian M, Jin G. CXCL12 inhibits cortical neuron apoptosis by increasing the ratio of $\mathrm{Bcl}-2 / \mathrm{Bax}$ after traumatic brain injury. Int $\mathrm{J}$ Neurosci. 2014;124(4):281-90. https://doi.org/10.3109/0020745 4.2013.838236

10. Nasiraei-Moghadam S, Kazeminezhad B, Dargahi L, Ahmadiani A. Maternal oral consumption of morphine increases $\mathrm{Bax} / \mathrm{Bcl}-2$ ratio and caspase 3 activity during early neural system development in rat embryos. J Mol Neurosci. 2010;41(1):156-64. https://doi.org/10.1007/ s12031-009-9312-6

11. Ren Z, Zhang R, Li Y, Li Y, Yang Z, Yang H. Ferulic acid exerts neuroprotective effects against cerebral ischemia/ 
reperfusion-induced injury via antioxidant and antiapoptotic mechanisms in vitro and in vivo. Int $\mathrm{J} \mathrm{Mol}$ Med. 2017;40(5):1444-56. https://doi.org/10.3892/ ijmm.2017.3127

12. Chowdhury S, Ghosh S, Das AK, Sil PC. Ferulic acid protects hyperglycemia-induced kidney damage by regulating oxidative insult, inflammation and autophagy. Front Pharmacol. 2019;10:27. https://doi.org/10.3389/ fphar.2019.00027

13. Wu W, Lee SY, Wu X, Tyler JY, Wang H, Ouyang Z, Park K, Xu XM, Cheng JX. Neuroprotective ferulic acid (FA)-glycol chitosan (GC) nanoparticles for functional restoration of traumatically injured spinal cord. Biomaterials. 2014;35(7):2355-64. https://doi.org/10.1016/j. biomaterials.2013.11.074

14. Li Z, Wang S, Li W, Yuan H. Ferulic acid improves functional recovery after acute spinal cord injury in rats by inducing hypoxia to inhibit microRNA-590 and elevate vascular endothelial growth factor expressions. Front Mol Neurosci. 2017;10:183. https://doi.org/10.3389/fnmol.2017.00183

15. Xu Y, Lin D, Yu X, Xie X, Wang L, Lian L, Fei N, Chen J, Zhu N, Wang G, Huang $X$, Pan J. The antinociceptive effects of ferulic acid on neuropathic pain: involvement of descending monoaminergic system and opioid receptors. Oncotarget. 2016;7(15):20455-68. https://doi. org/10.18632/oncotarget.7973

16. Zhao $Y Z$, Jiang $X$, Xiao J, Lin $Q$, Yu WZ, Tian FR, Mao $\mathrm{KL}$, Yang $\mathrm{W}$, Wong $\mathrm{HL}$, Lu CT. Using NGF heparinpoloxamer thermosensitive hydrogels to enhance the nerve regeneration for spinal cord injury. Acta Biomater. 2016;29:71-80. https://doi.org/10.1016/j. actbio.2015.10.014

17. Dinh P, Hazel A, Palispis W, Suryadevara S, Gupta R. Functional assessment after sciatic nerve injury in a rat model. Microsurgery. 2009;29(8):644-9. https://doi. org/10.1002/micr.20685

18. Zhang HY, Wang ZG, Wu FZ, Kong XX, Yang J, Lin BB, Zhu SP, Lin L, Gan CS, Fu XB, Li XK, Xu HZ, Xiao J. Regulation of autophagy and ubiquitinated protein accumulation by bFGF promotes functional recovery and neural protection in a rat model of spinal cord injury. Mol Neurobiol. 2013;48(3):45264. https://doi.org/10.1007/s12035-013-8432-8

19. Ojha S, Javed H, Azimullah S, Abul Khair SB, Haque ME. Neuroprotective potential of ferulic acid in the rotenone model of Parkinson's disease. Drug Des Devel Ther. 2015;9:5499-510. https://doi.org/10.2147/DDDT.S90616

20. Ge LJ, Fan SY, Yang JH, Wei Y, Zhu ZH, Lou YJ, Guo Y, Wan HT, Xie YQ. Pharmacokinetic and pharmacodynamic analysis of ferulic acid-puerarin-astragaloside in combination with neuroprotective in cerebral ischemia/reperfusion injury in rats. Asian Pac J Trop Med. 2015;8(4):299-304. https://doi. org/10.1016/S1995-7645(14)60334-5

21. K MD, Muralidhara. Neuroprotective efficacy of a combination of fish oil and ferulic acid against 3-nitropropionic acid-induced oxidative stress and neurotoxicity in rats: behavioural and biochemical evidence. Appl Physiol Nutr Metab. 2014;39(4):487-96. https://doi.org/10.1139/apnm-2013-0262

22. Jiang X, Liu J, Lin Q, Mao K, Tian F, Jing C, Wang C, Ding L, Pang C. Proanthocyanidin prevents lipopolysaccharide-induced depressive-like behavior in mice via neuroinflammatory pathway. Brain Res Bull. 2017;135:40-6. https://doi. org/10.1016/j.brainresbull.2017.09.010

23. Park HH, Lee S, Oh JM, Lee MS, Yoon KH, Park BH, Kim JW, Song $\mathrm{H}$, Kim SH. Anti-inflammatory activity of fisetin in human mast cells (HMC-1). Pharmacol Res. 2007;55(1):317. https://doi.org/10.1016/j.phrs.2006.10.002

24. Wang B, Dai W, ShiL, Teng H, LiX, WangJ, GengW. Neuroprotection by paeoniflorin against nuclear factor kappa B-induced neuroinflammation on spinal cord injury. Biomed Res Int. 2018;2018:9865403. https://doi.org/10.1155/2018/9865403

25. Liang Y, Zhou Y, Shen P. NF-kappaB and its regulation on the immune system. Cell Mol Immunol. 2004;1(5):343-50.

26. Zhang $H$, Xiang $Z$, Duan $X$, Jiang JL, Xing YM, Zhu C, Song $Q, Y u Q R$. Antitumor and anti-inflammatory effects of oligosaccharides from Cistanche deserticola extract on spinal cord injury. Int J Biol Macromol. 2019;124:360-7. https://doi.org/10.1016/j.ijbiomac.2018.11.132

27. Hassanzadeh $S$, Jameie $S B$, Soleimani $M$, Farhadi $M$, Kerdari M, Danaei N. Coenzyme Q10 influences on the levels of TNF-alpha and IL-10 and the ratio of $\mathrm{Bax} / \mathrm{Bcl} 2$ in a menopausal rat model following lumbar spinal cord injury. J Mol Neurosci. 2018;65(2):255-64. https://doi. org/10.1007/s12031-018-1090-6

28. Esposito E, Cuzzocrea S. Anti-TNF therapy in the injured spinal cord. Trends Pharmacol Sci. 2011;32(2):107-15. https://doi.org/10.1016/j.tips.2010.11.009

29. Bauer MK, Lieb K, Schulze-OsthoffK, Berger M, Gebicke-HaerterPJ, Bauer J, Fiebich BL. Expression and regulation of cyclooxygenase-2 in rat microglia. Eur J Biochem. 1997;243(3):726-31. https://doi. org/10.1111/j.1432-1033.1997.00726.x

30. Colasanti M, Persichini T, Menegazzi M, MariottoS, Giordano E, Caldarera CM, Sogos V, Lauro GM, Suzuki H. Induction of nitric oxide synthase mRNA expression. Suppression by exogenous nitric oxide. J Biol Chem. 1995;270(45):267313. https://doi.org/10.1074/jbc.270.45.26731

31. Lopez-Vales R, Garcia-Alias G, Guzman-Lenis MS, Fores J, Casas C, Navarro X, Verdú E. Effects of COX-2 and iNOS inhibitors alone or in combination with olfactory ensheathing cell grafts after spinal cord injury. Spine (Phila Pa 1976). 2006;31(10):1100-6. https://doi.org/10.1097/01. brs.0000216448.61860.1d

32. Hains BC, Yucra JA, Hulsebosch CE. Reduction of pathological and behavioral deficits following spinal cord contusion injury with the selective cyclooxygenase-2 inhibitor NS-398. J Neurotrauma. 2001;18(4):409-23. https://doi.org/10.1089/089771501750170994 
33. Chatzipanteli K, Garcia R, Marcillo AE, Loor KE, Kraydieh $S$, Dietrich WD. Temporal and segmental distribution of constitutive and inducible nitric oxide synthases after traumatic spinal cord injury: effect of aminoguanidine treatment. J Neurotrauma. 2002;19(5):639-51. https://doi. org/10.1089/089771502753754109

34. Beattie MS, Farooqui AA, Bresnahan JC. Review of current evidence for apoptosis after spinal cord injury. J Neurotrauma. 2000;17(10):915-25. https://doi.org/10.1089/ neu.2000.17.915

35. Ichim G, Tauszig-Delamasure S, Mehlen P. Neurotrophins and cell death. Exp Cell Res. 2012;318(11):1221-8.

36. Reed JC. Double identity for proteins of the $\mathrm{Bcl}-2$ family. Nature. 1997;387(6635):773-6. https://doi.org/10.1038/ 42867
37. Sun Y, Liu D, Su P, Lin F, Tang Q. Changes in autophagy in rats after spinal cord injury and the effect of hyperbaric oxygen on autophagy. Neurosci Lett. 2016;618:139-45. https://doi. org/10.1016/j.neulet.2016.02.054

38. Antonioli M, Di Rienzo M, Piacentini M, Fimia GM. Emerging mechanisms in initiating and terminating autophagy. Trends Biochem Sci. 2017;42(1):28-41. https://doi.org/10.1016/j. tibs.2016.09.008

39. Maiuri MC, Criollo A, Kroemer G. Crosstalk between apoptosis and autophagy within the Beclin 1 interactome. EMBO J. 2010;29(3):515-6.

40. Xie L, Yu S, Wang Z, Yang K, Liu Z, Li C, Liang Y. Nicotinamide adenine dinucleotide protects against spinal cord ischemia reperfusion injury-induced apoptosis by blocking autophagy. Oxid Med Cell Longev. 2017;2017:7063874. https://doi.org/10.1155/2017/7063874 